\title{
Compressive Strength Improvement and Admixture Potential of Palm Tree Liquor Juice Extract (Ogogoro) in Cement Mortar and Concrete
}

\author{
Amaziah Walter Otunyo*, Ukeh Festus Sunday, Nkani Cosmas Milo \\ Department of Civil Engineering, Rivers State University, Nkpolu, Port Harcourt, Nigeria \\ *Corresponding author: umutuigili@yahoo.com
}

\begin{abstract}
This paper is the result of the investigation of the potential of a local gin, brewed in Nigeria from palm tree liquor juice, for compressive strength improvement and as an admixture in concrete and cement mortar. It was observed from the analysis of the results of the experiment that $5-10 \%$ of the local gin also called "ogogoro" increases the compressive strength of concrete and acts as an admixture (accelerator and retarder at various concentrations) in both concrete and mortar respectively.
\end{abstract}

Keywords: admixture, compressive strength, concrete, flexural strength, local gin, mortar, setting time, split tensile strength, water absorption

Cite This Article: Amaziah Walter Otunyo, Ukeh Festus Sunday, and Nkani Cosmas Milo, "Compressive Strength Improvement and Admixture Potential of Palm Tree Liquor Juice Extract (Ogogoro) in Cement Mortar and Concrete." American Journal of Civil Engineering and Architecture, vol. 5, no. 6 (2017): 245-252. doi: 10.12691/ajcea-5-6-4.

\section{Introduction}

To satisfy the needs of modern civilization, continuous research works are being devoted to the development of new and low cost materials with specific properties [1].

Palm wine juice is extracted from regular palm trees and Raphia palm trees in Nigeria and some other parts of West Africa and is copiously consumed because of its freshness, taste and relatively low cost. Distillation of this same palm wine juice gives rise to a local liquor (gin), commonly called "ögogoro"

"Ogogoro", a local liquor (gin) is a West African alcoholic drink, usually distilled locally from Raphia palm tree juice. It is most popular in Nigeria, where it is known as the country's home brewing [2]. The active ingredient in the local liquor (gin) "ogogoro"is ethanol, whose concentration within the drink is very high (48\%). The drink can be extremely dangerous as a result of the fact that it is often home-brewed by amateurs. Indeed it is said that hundreds die every year from improperly brewed "ögogoro". The fact that it is detrimental to living when it is improperly produced is the reason for determining its effect on mortar and concrete properties. This is with a view to finding some useful application for such liquor that is cheaply produced in abundance in West Africa but has dangerous effect on humans when brewed by both amateurs. The professionally brewed types serve as liquor and the useful application in concrete is being investigated in this study.

Palm trees are abundant in the riverine areas of the Niger Delta of Nigeria and represent the main source of lignocelluosic materials in the area. Lignin refers to a group of phenolic polymers that confer rigidity to the woody cell wall of plants. Its chemical and physical properties differ depending on the plant type and the extraction method $[3,4]$ and can serve a lot of purposes as binder, dispersant and emulsifiers [5,6,7]. Lignosulphonates have been shown to have the potential of workability aid for cement $[8,9]$. The sulphonation process is very expensive and difficult [10-16].

[17] (Singh, et al) carried out an experiment on the effect of furfurly alcohol on the properties on hydrated cement mortar, they concluded that furfurly alcohol acts as an accelerator

Alcohol increases the rate of hydration in cement and enhances the strength o concrete [18]. Although there are little or no reports of use of palm liquor as a workability aid for mortar and concrete, the use of black liquor show that alkali black liquor does not have any negative effect on concrete durability or steel corrosion [19,20] and [21] and can be treated using microbial community [22,23,24].

[25] (Scolfani and Contrafato) observed that Polyvinyl Alcohol (PVA) is set/type of alcohol which when applied in concrete, changes its strength either positively or negatively. Ployvinyl alcohol is a water-soluble polymer which has gained more attention in recent years due to its potential for industrial applications. In spite of its importance, it has been less studied as a cement modifying agent and there is very few literature devoted to cement-polymer composites.

[26] (Singh, et al) also studied the effect of hydroxyl propyl methyl cellulose (HPMC) on the properties of cement. They concluded that HPMC acts as a retarder in concrete. 
The two studies mentioned above corroborate the fact that different types of alcohol can act as either a retarder or an accelerator in concrete. This observation also follows the observation of [27] who investigated the concrete admixture and set retarder potential of palm liquor itself (not the product of its distillation, which is "ogogoro"- local gin).and concluded that palm liquor for example, increases concrete workability, improves compaction, reduces combing and retards the initial and final setting time of concrete.

[1] also studied the effect of polyvinyl alcohol on flexural strength and some important physical properties of Portland Cement paste. They concluded that flexural strength and important physical properties of Portland cement paste including permeable pore volume and water absorption can be significantly improved by addition of polyvinyl alcohol. It was also observed that the positive effect of PVA on cement paste workability is mainly interpreted in terms of improved consistency due to both the "ball-bearing" action and dispersing effect of polymer. Relatively high Polymer to Cement ratio however, reduce the paste workability due to increase in paste viscosity. The water/cement ratio consistency (flow or slump) can therefore be markedly reduced by modifying it with a suitable proportion of PVA. This water reduction effect is found to contribute to a strength development and drying shrinkage reduction [28].

[29] (Bright et al) investigated the influence of various polymeric materials on the physical properties of a cementitious patching compound and observed that a lower water/cement ratio results in a decrease

[1] also observed that lower water/cement of 0.28 , addition of polymer does not provide any improvement in flexural strength, but also decreases the flexural strength slightly. It was also found out that water absorption reduces considerably with increase in Polymer/Cemenmt ratio.

A $2 \%$ weight $\%$ polymer addition can reduce the water absorption to half of the value obtained for the unmodified paste. This indicates that the polymer addition results in reduction of the porosity of the pastes.

[30] (Shaker et al) in their studies concluded that (i) principle of latex modification and some typical properties of latex modified mortar and concrete, respectively confirmed that the polymer fills the voids in the cement matrix which results in the reduction of porosity. (ii) durability of styrene butadiene latex modified concrete.

The product of the distillation of the palm liquor juice (local gin - ögogoro”) is readily and cheaply available in Nigeria. This investigation is aimed at exploring its potential in mortar and concrete. Tremendous saving in foreign exchange will be made in Nigeria from the use of "ogogoro" in mortar and concrete production.

\section{Materials and Method}

\subsection{Materials}

\subsubsection{Cement}

The cement used in the study was OPC (Grade 42.5) produced at DANGOTE CEMENT INDUSTRIES Plc. It conformed to [31].

\subsubsection{Fine Aggregate}

Fine aggregate used was obtained from clean river sand at Oyigbo, a suburb of Port Harcourt. The maximum size was $4.75 \mathrm{~mm}$. Impurities were removed and it confirmed to the requirements of [32]).

\subsubsection{Coarse Aggregate}

Coarse aggregate used is crushed angular and rough textured granite obtained from Ishiagu in Ebonyi State in South Eastern Nigeria. Maximum size was $20 \mathrm{~mm}$. It met the requirements of [32].

\subsubsection{Water}

Potable water used was obtained from the Civil Engineering Laboratory of the Rivers State University, Nkpolu, Orowuruku, Port Harcourt. It met the requirements of [33].

\subsubsection{Distillate of Palm liquor Juice (Local gin- "Ogogoro")}

The distillate of palm liquor juice also known as “ogogoro" was obtained from Kaima a town located along the East-West Road between Port Harcourt and Warri. It was confirmed to be $! 00 \%$ alcohol by lighting a match and burning the liquid and also from Laboratory test.

\subsection{Method}

The investigation involved replacing water with various percentages $(0 \%, 5 \%, 10 \%, 20 \%$ and $30 \%)$ of the local gin. in both the cement mortar and concrete.

\subsubsection{Sieve Analysis Test}

Particle Size Distribution or sierve analysis test were carried out on the fine (sand) and coarse (granite) aggregates in accordance with [34]

\subsubsection{Workability}

Slump test was carried out on the cement mortar and concrete with the local gin replacing water in the following percentages ( $0 \%$, 5\%, 10\%, 20\% and 30\%). This was done in accordance with [35].

\subsubsection{Setting Times}

Initial and final setting times were determined for the cement mortar with various percentages of the local gin. This was performed in accordance with [36]

\subsubsection{Compressive Strength Test}

A total of 90 cubes were cast, 45 each respectively for the cement mortar and concrete compressive strength tests. Compressive Strength of the cement mortar and concrete was determined at 7, 14 and 28 days. The water/cement ratio used for the concrete cubes is 0.5 and the mix ratio was 1:2:4.

The size of the cubes was $150 \mathrm{~mm} \times 150 \mathrm{mmx} 150 \mathrm{~mm}$. Test was performed in accordance with (BS 1881-116; 1983). Table 1 shows the Concrete Mix Design for the Compressive Strength. The test was performed in accordance with [37]. 


\subsubsection{Flexural Strength Test (Concrete)}

45 concrete beams of dimension $100 \mathrm{~mm}$ x $100 \mathrm{~mm} \times$ $500 \mathrm{~mm}$ were cast for the (\%, 5\%, 10\%, 20\% and 30\%). alcohol/water- replacement ratios. The flexural strength of the concrete beams was determined at 7, 14 and 28 days, in accordance with [38].

\subsubsection{Split Tensile Strength (Concrete)}

45 cylindrical concrete cubes of dimension diameter $150 \mathrm{~mm}$, height $300 \mathrm{~mm}$ were cast for the $(\%$, 5\%, $10 \%$, $20 \%$ and $30 \%$ ). alcohol/water-replacement ratios. The split tensile strength of the cylindrical cubes was determined at 7 , 14 and 28 days, in accordance with [39]

\subsubsection{Water absorption (Concrete)}

Water absorption of the concrete cubes cast with partial replacement of water with the local gin was measured at 7 , 14 and 28 days. [40].

\section{Results and Discussions}

\subsection{Chemical Composition of the local gin "ogogoro"}

The result of the physiochemical analysis of the local gin is shown in Table 1.

The results for the mortar and concrete is presented separately.

\subsection{Cement Mortar}

\subsubsection{Setting Times}

Figure 1 shows a plot of the initial and final setting times for the $(0 \%, 5 \%, 10 \%, 20 \%$ and $30 \%)$ partial replacement of water with local gin. in the cement mortar. It was observed that the initial and final setting times decreased between 5\% and 10\% replacement of water with the local gin. It therefore follows that the local gin is an accelerator at quantities between 5\% and 10\% volume replacement of water with the local gin. The high concentration of ethanol which is an amphoteric compound (ability to behave as acid in strong base medium and basic in strong base medium. The ethanol hastens the hydration process leading to early hardening. The main action of the accelerator occurs in the plastic state of the cement paste, while in the later case the accelerator is primarily in the hardened state. [41]

\subsubsection{Compressive Strength}

Figure 2 is the result of the compressive strength of the cement mortar for the $(0 \%, 5 \%, 10 \%, 20 \%$ and $30 \%)$ local gin/water cement mortars at 7, 14 and 28 days. For all the curing periods, the compressive strength decreased as from $5 \%$ - $10 \%$ local gin and water content. This corresponds to the observation of [38].ethanol is reacting in acid medium to form a base and accelerating the hardening process at between $0 \%-5 \%$, thereafter. At 7 and 14 days, The compressive strength started to increase between $10 \%$ - $20 \%$ local gin content. At this stage the local gin behaves like a retarder by being absorbed at the solid-water interface of cement grains or their hydration products. The absorbed retarder molecules block or delay further contact of the unhydrated cement with water and therefore retard the hydration of the cement. [42]

\subsection{Concrete Cubes}

\subsubsection{Sieve Analysis}

Figure 3 shows the result of the sieve analysis of the fine and coarse aggregates. The results show that the normal coarse aggregates ranged in particle sizes of $4.75-20 \mathrm{~mm}$, while the particle sizes of of the fine aggregate were those passing the $44.75 \mathrm{~mm}$ sieve and retained on the 75um sieve.

Table 1: Physiochemical Composition Of local gin

\begin{tabular}{|c|c|c|c|c|}
\hline S/No & Parameter & Test Method & Result & Standard \\
\hline 1 & $\mathrm{pH}$ & APHA 4500HB & 6.46 &.$>5$ \\
\hline 2 & Acidity (KOH/g) & ASTM D664 & 0.51 & 1.0 Max \\
\hline 3 & Specific gravity@ $15^{\circ} \mathrm{c}$ & IP 160 & 0.78 & $0.7-0.8$ \\
\hline 4 & Total Soluble Solids (mg/kg) & APHA 2510B & NIL & $0.5 \mathrm{Max}$ \\
\hline 5 & Refractive Index & NIS 235 & 1.3610 & - \\
\hline 6 & Ethanol content (\%) & NIS 235 & 84.0 & - \\
\hline 7 & Colour & Visual & colourless & colourless \\
\hline 8 & Boiling Point ${ }^{{ }^{\circ} \mathrm{C}}$ & ASTM D86 & 75.0 & 80.0 Max \\
\hline 9 & Viscosity (cst) & IP 74 & 1.84 & $1.77-2.0$ \\
\hline 10 & Water Content (\%) & IP 74 & 0.96 & 5.0 Max \\
\hline 11 & Sugar Content (\%) & NIS 235 & NIL & 0.00 \\
\hline 12 & Carbohydrate (mg/kg) & NIS 235 & 0.16 & 1.0 \\
\hline 13 & Iron (mg/kg) & NIS 235 & 0.08 & 5.0 \\
\hline 14 & Appearance & VISUAL & Bright & Bright \\
\hline 15 & Sulfur (mg/kg) & NIS 235 & $<0.01$ & 2.0 \\
\hline 16 & COD (mg/l) & APHA 5220D & 109.44 & 40.0 \\
\hline 17 & BOD (mg/l) & APHA 5210D & 91.2 & 10.0 \\
\hline
\end{tabular}




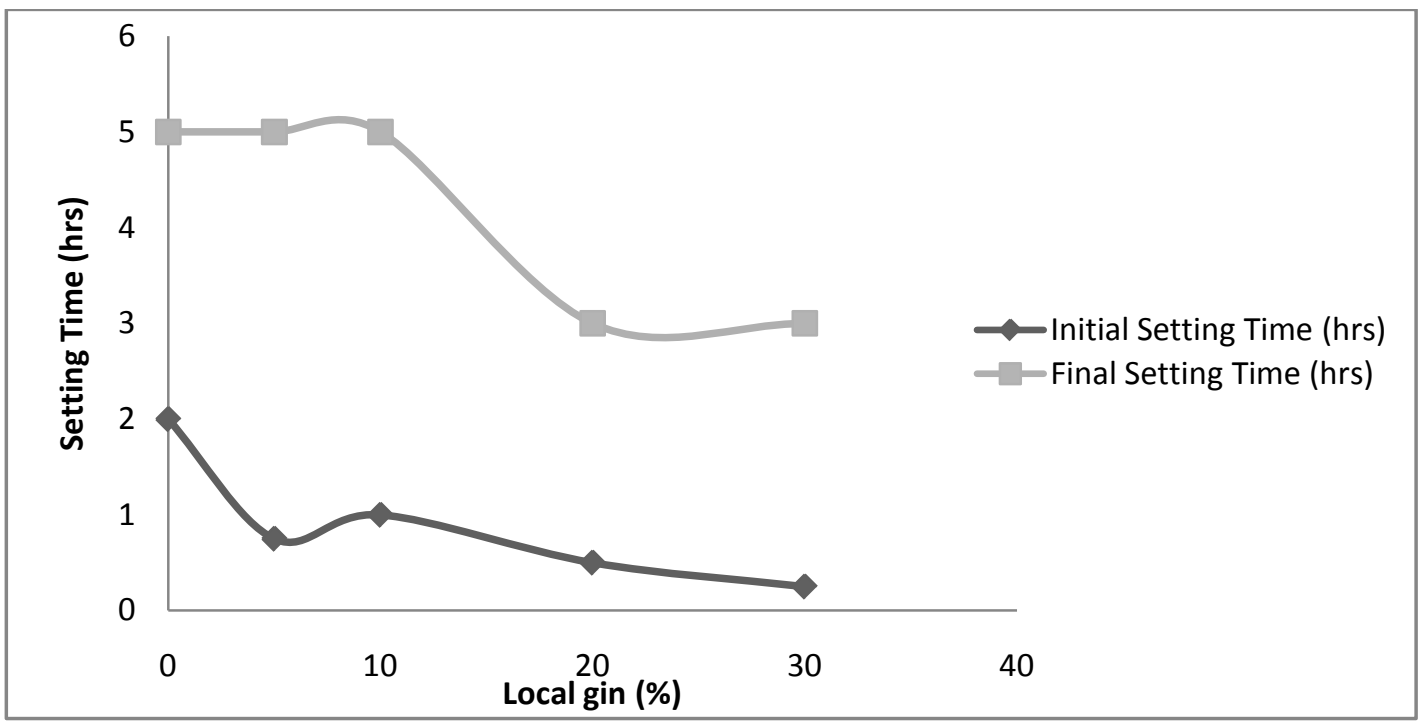

Figure 1. Setting Time of mortar versus the percentage of local gin

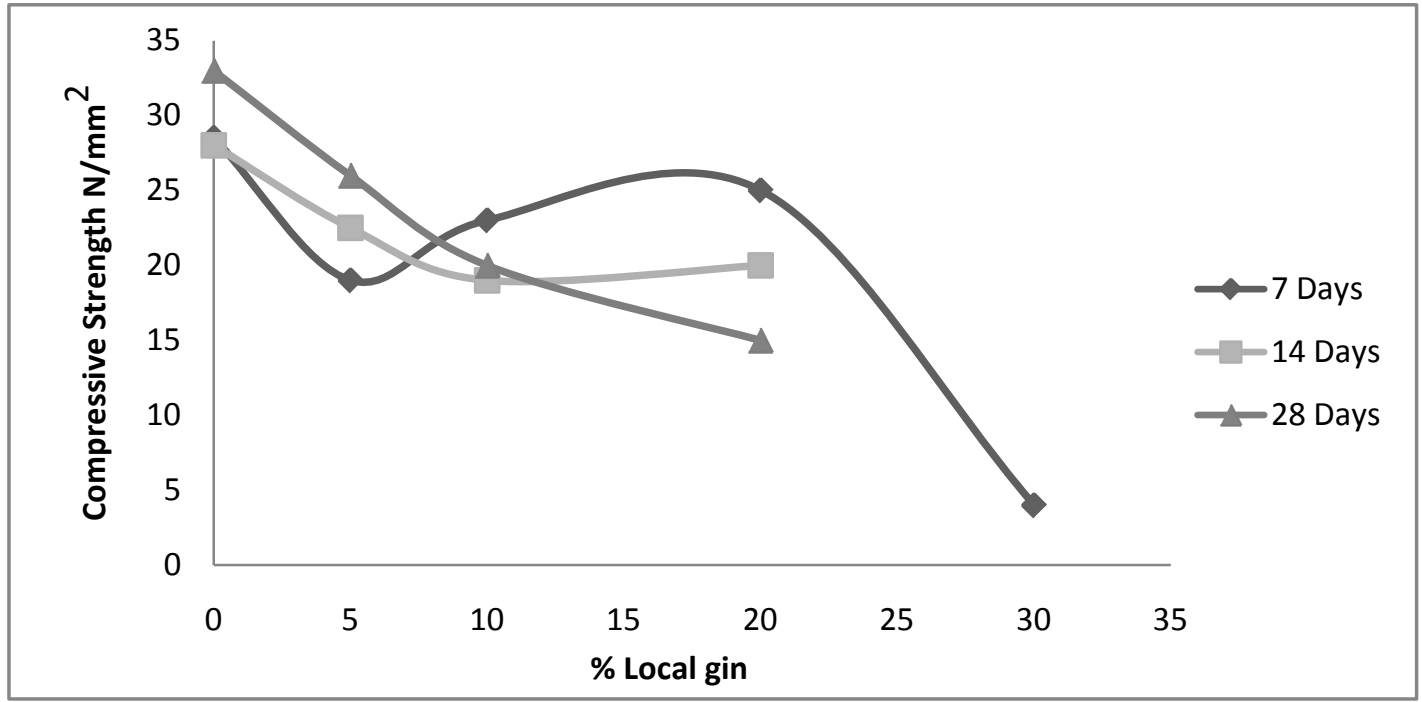

Figure 2. Compressive strength of mortar versus percentage of local gin

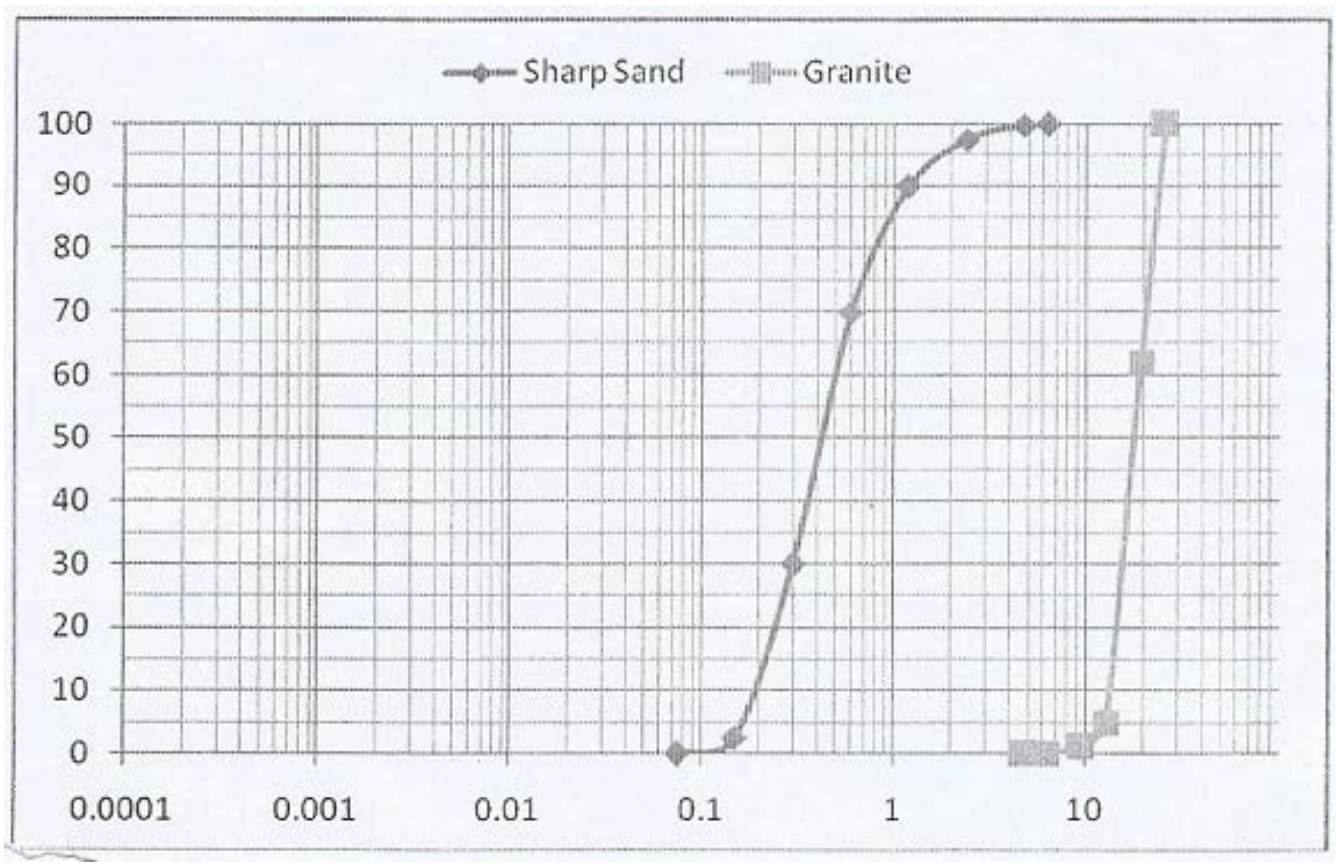

Figure 3. Particle Size Distribution Curves for Fine and Coarse Aggregates 


\subsubsection{Setting Time}

Figure 4 is the plot of the initial and final setting times versus the various percentages of local gin/water in the concrete cubes. Between 0\% - 10\% local gin content, the initial and final setting times decreased as the local gin content was increasing. Between $10 \%$ to $30 \%$ local gin content the initial and final setting times were not affected by the increase in local gin content. The reason for the result is as explained for the setting time of the cement mortar in section 3.2.1.

\subsubsection{Compressive Strength}

Figure 5 is the plot of the compressive strength against the various percentages of water replacement with local gin at 7, 14 and 28 days respectively. At all ages of curing, the compressive strength increases as the local gin content increases within 5\% - !0\% local gin content. At 20\% local gin content and for 14 and 28 days curing period, the compressive strength commences an increase as the local gin content increases and peaks at 30\% local gin content. The explanation for the behavior at between $20 \%$ - 30\% local gin content is not readily deduced. However, the result at between $5 \%-10 \%$ local gin content is in line with that of the cement mortar and has been similarly observed by [39] Alcohols generally belong to the hydroxyl group. At certain percentage content they tend to increase the hydration process in concrete and enhances strength [18].

\subsubsection{Flexural Strength}

The plot of the flexural strength versus the percentage replacement of water with local gin at 28 days is shown in Figure 6. There is an increase in flexural strength between $5 \%-10 \%$ local gin content. At this level of local gin content the ethanol is behaving like a retarder [42], thereafter, the flexural strength decreased as the local gin content is increased at this level of local gin content, ethanol is behaving like an accelerator [41].

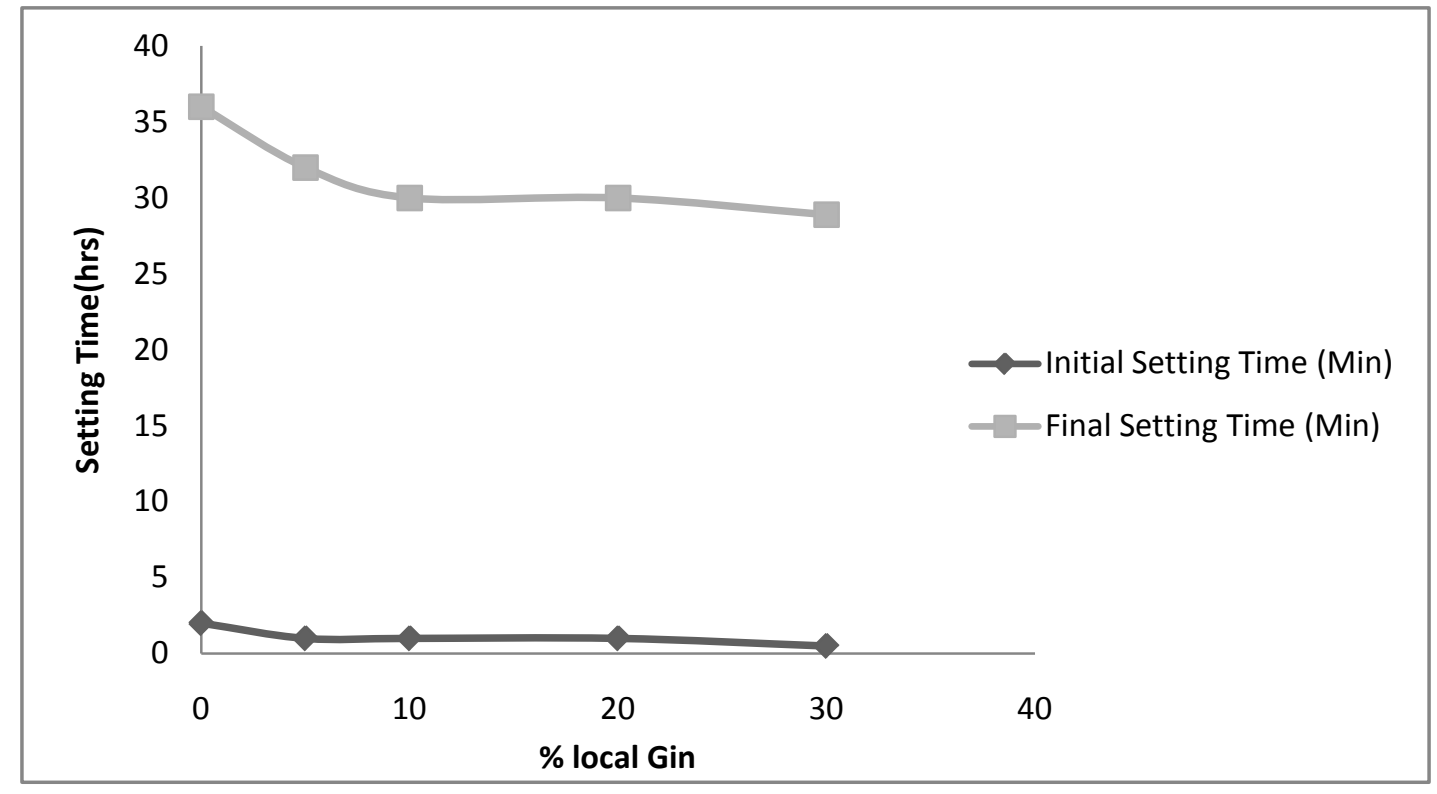

Figure 4. Setting Time of concrete versus the percentage of local gin

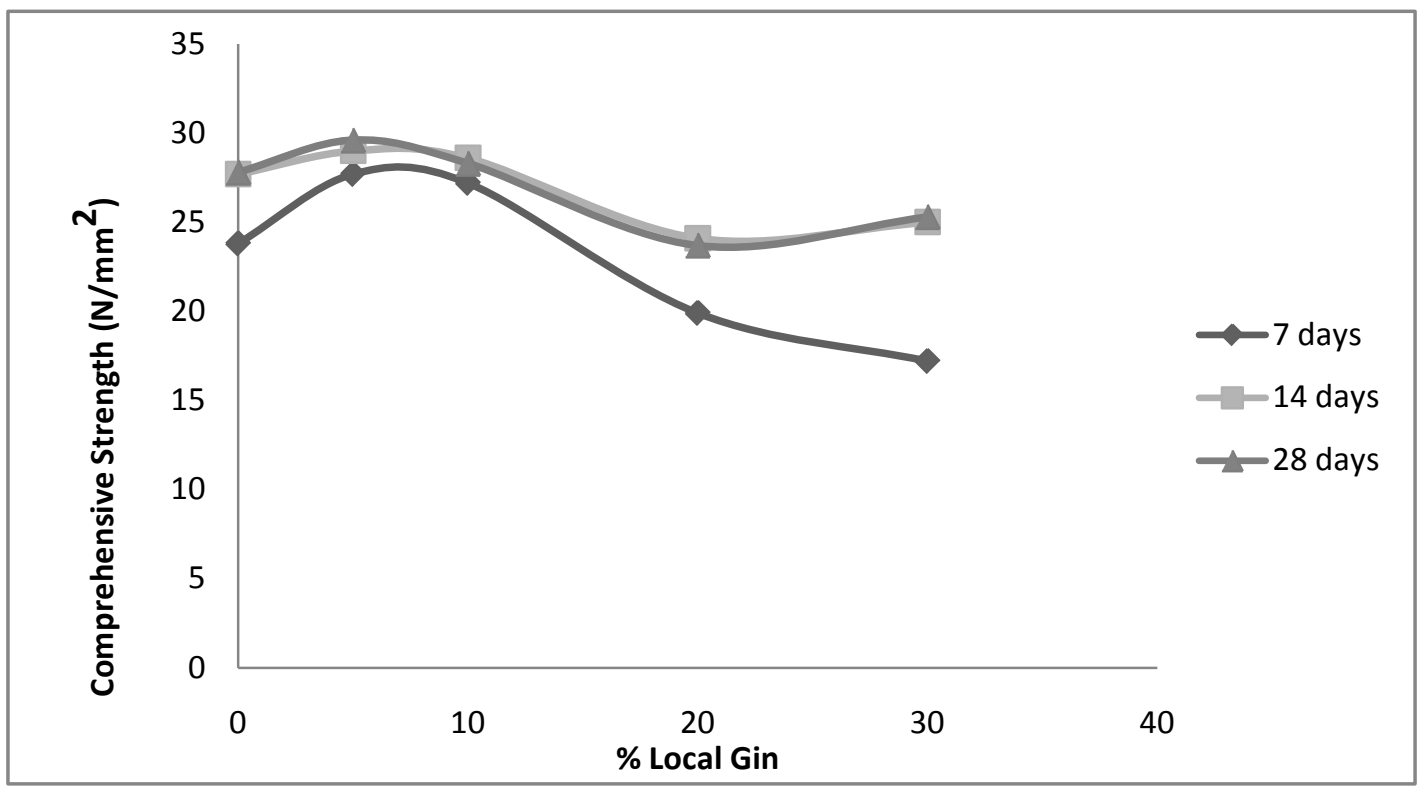

Figure 5. Compressive strength of concrete versus percentage of local gin 


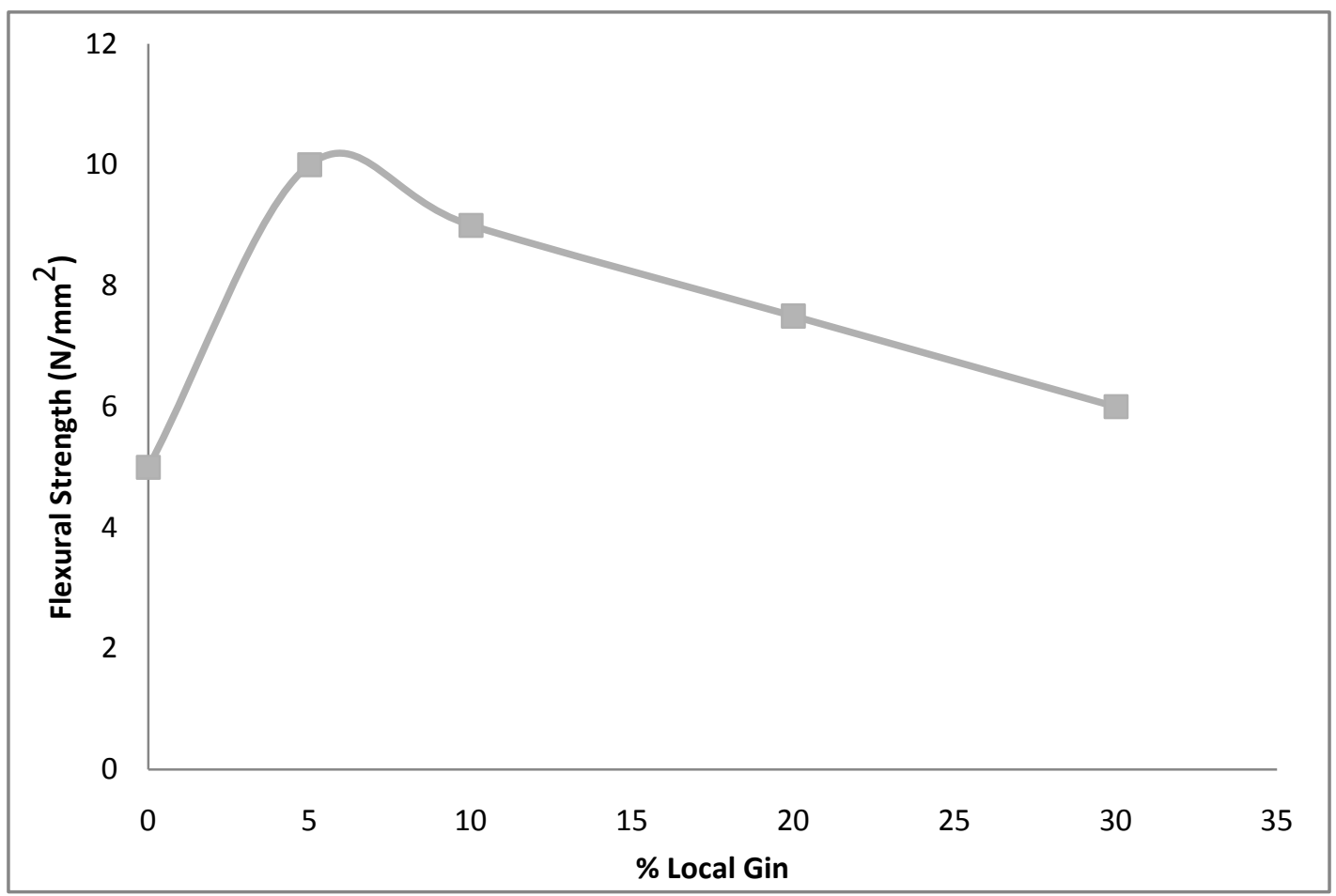

Figure 6. Flexural Strength of concrete versus percentage of local gin

\subsubsection{Split Tensile Strength}

As can be observed from Figure 7, the split tensile strength at 28 day increases between 5\%-10\% local gin content, thereafter, the split tensile strength decreased as the local gin content is increased. The explanation for the compressive strength and flexural strength, also apples in this case.

\subsubsection{Water Absorption}

Figure 8 shows the graph of percentage water absorption against the percentage local gin content at 7, 14 and 28 days curing period. The percentage water absorption decreases as the percent local gin content increases up till $10 \%$ local gin content when it starts to increase. This trend was noticed for all curing periods. At concentrations of the local gin up to $10 \%$, the local gin is acting as a hydrophobic agent. Hydrophobic agents are surface protection materials capable of increasing the angle of contact between the water and the concrete. For this reason hydrophobic agents reduce water (in liquid form) penetration in concrete. [43]. At 20\% local gin content and 7 days curing period, the water absorption increases as the percentage of local gin is increased. The ethanol in the concrete starts behaving as a non-hydrophobic agent.

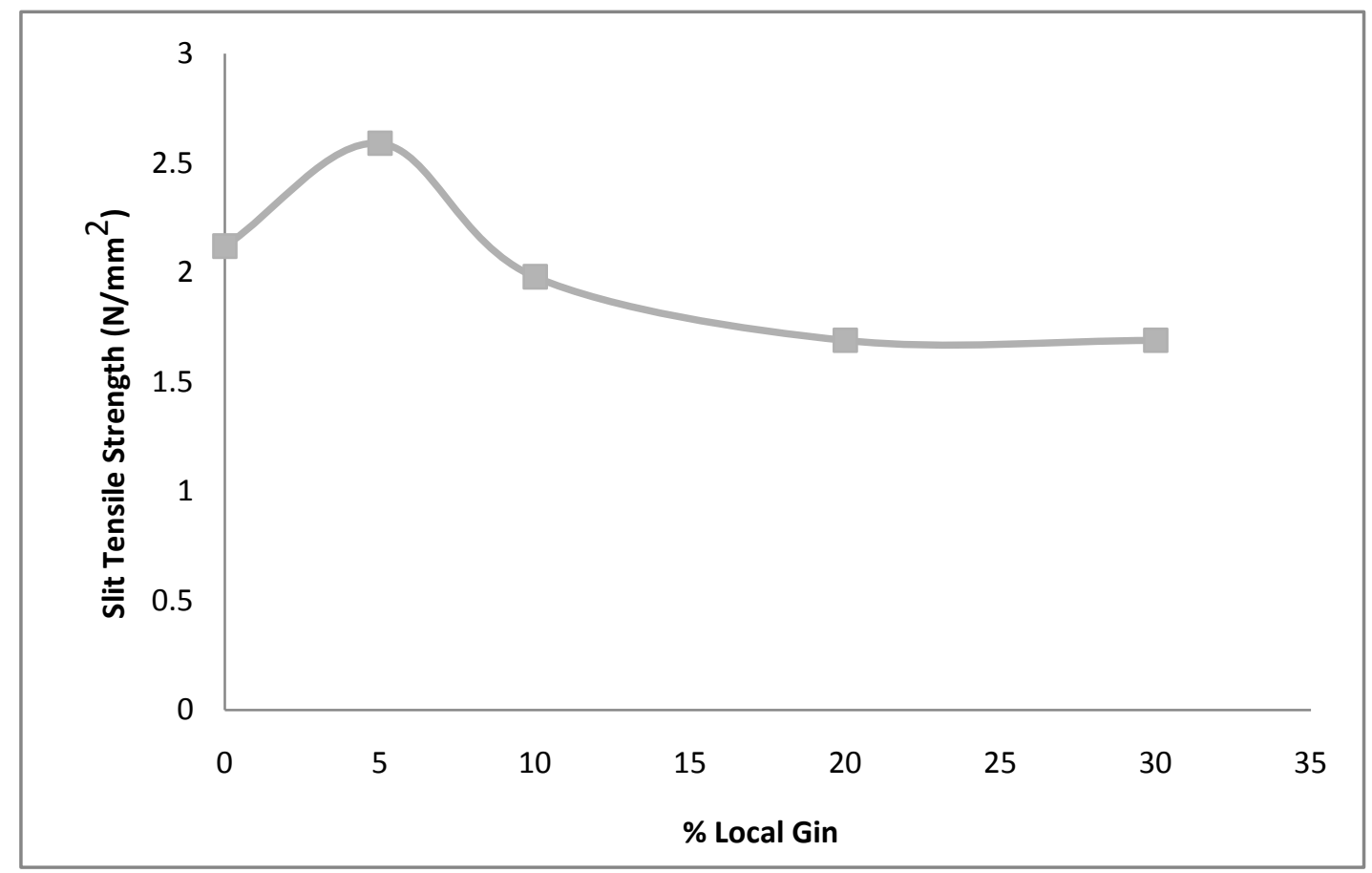

Figure 7. Split Tensile Strength of concrete versus percentage of local gin 


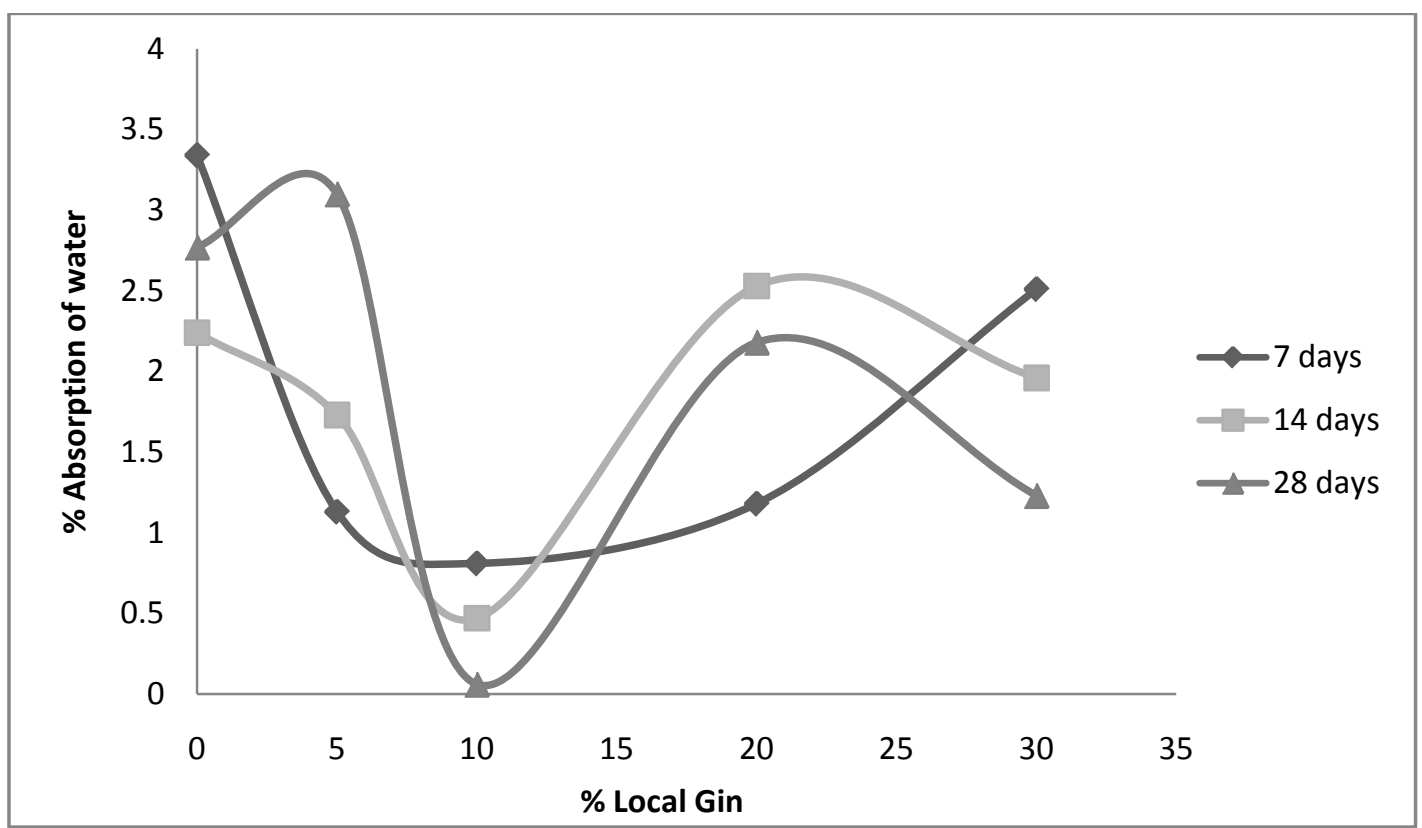

Figure 8. Percemntage water absorption of concrete versus percentage of local gin

\section{Conclusion}

(i) The local gin can be used as an admixture (accelerator) in cement mortar and concrete production at between $5 \%-10 \%$ local gin content in water.

(ii) At between $5 \%$ local gin content in water, the compressive strength increases by about $16.5 \%, 5 \%$ and $6.5 \%$ respectively at 7,14 and 28 days curing period, while at $10 \%$ local gin content the compressive strength increase by about $14 \%, 3 \%$ and $25 \%$ respectively at 7,14 and 28 days curing period

(iii) The values of the compressive strength, flexural strength, split tensile strength decrease after 5\%-10\% local gin content. The increase at this percentage is as explained by [41], - ethanol accelerating the hydration process. The decrease in the compressive, flexural and split tensile strength is due to role reversal - ethanol being involve in the "coating theory"- ethanol acting as a retarder by being absorbed at the solid-water interface of cement grains or their hydration products and subsequently slowing the hydration process [42].

(iv) Addition of local gin up to 5\% reduced the amount of water absorption in the concrete. This is due to the ethanol acting as a hydrophobic agent [43].

(v). The water absorption did not exceed $7 \%$, which is in accordance with [44].

(vi) Mortar and concrete setting at the various percentages of the local gin content revealed that cement mortar and concrete sets faster as the percentage of the local gin increases from 5\% - 30\%. This is attributed to the high ethanoic constituent in the reaction with limestone present in the cement which causes rapid hardening. [41]

(vii) The optimum compressive, flexural and split tensile strength, percentage water absorption and setting times occurred at 5\% replacement of water with local gin.

\section{Abbreviations}

APHA- American Public Health Association
ASTM - American Standards for Testing of Materials BS - British Standards HPMC - Hydroxyl Propyl Methyl Cellulose IP - Institute of Polution

NIS- Nigerian Industrial Standards

PVC - Poly Vinyl Acohol.

\section{References}

[1] Allahverdi, A. Kianpur, K. and Moghbelli, M.R. Effect of polyvinyl alcohol on flexural strength and some important physical properties of portland cement paste. Iranian Journal of Material Science \& Engineering, 7(1), 2010.

[2] Heap, S. Those that are cooking the gins. The business of ogogoro in Nigeria, Contemporary Drug Problems, 35(4): pp 573-610, 2008.

[3] Mark, H.F and Gaylord, N.G. Encyclopedia of polymer science and technology. New York: Wiley, 1968.

[4] Rance, H.F. Handbook of paper science. New York: Elsevier, 1980.

[5] Bancher, M, Halpin, C.Petit C omil, M, and Boerjan, W., L., Genetic engineering and impact on pulping, Crit Rev Biochem Mol Biol, 38(4): 305-355, 2003.

[6] Wrobel, K.M., Starzycki, J. Oszmianski, J. and Szopa, J. Lignin deficiency in transgenic flax resulted in plants with improved mechanical properties, Journal of Biotechnology, 128(4): 919-943, 2007.

[7] Pan, C.Y. and Kung, L.Z., Polymer 49, 200-210, 2008.

[8] American Concrete Institute. ACI Committee 212 .Admixtures for concrete, 3(5), 24-52, 1981.

[9] El sheref, S. Safety and economy in reinforced concrete. $1^{\text {st }}$ ed. Cairo: El-Tawwed Publisher \& Distributors, 1988.

[10] Myreen, B. Process for recovering alkali and black liquor containing silicate. US Patent 6183598, Available at: http://www.patentstorm.us/patents/6183598.html. 2001(a).

[11] Myreen, B. A new approach to the non-wood black liquor problem. Proceeding of the TAPPI Pulping conference; Seattle, 2001(b).

[12] El Shaal, H. Process for treating spent, waste, alkalibne digestion liquor from paper pulping operations and product. US Patent 6632327. Available at http://www.freepatentsonline.com/6632327.hmtl, 2003.

[13] El shaal, H., El Sayed, A. Treatment of spent pulping liquor with lignin separation to recover alkali pulping chemicals in manufacture of paper pulp. US. Patent 6830696. Available at: http://www.patentstorm.us/patents/6183598.html.2004. 
[14] Guang, L. Yangsheng, L. Jinren, N., Hanchang, S., and Yi, O. Treatability of ktaft spent liquor by microfiltration and ultrafiltration. Desalination; 160(2), 131-172.

[15] Hassan, M/L and Nada, A.A.M.A, Utilization of lignocellulosic fibres in moulded polyester composites, Journal of Applied Polymer Science, 87(4), 653-713, 2003.

[16] Bhattacharjee, S.Datta, S. and Battacharjee, C. Performance study during ultrafiltration of ktaft black liquor using rotating disk membrane module. J. Cleaner Production, 14(5), 497-504, 2006.

[17] Singh, R. K., Khatri, S.D. and Singh, R.K. Effect of furfurly alcohol on the properties of hydrated cement mortar. Journal of Materials Research, 5(x), 2003.

[18] Zheng, Z. and Feldman, D. Synthetic fibre-reinforced concrete. Progress in Polymer Science, 20(2), 185-210, 1995.

[19] Ali, A.H. The effect of a waste-products mix on concrete strength and corrosion protection of steel reinforcement in sulphate media. Corrosion prevenionn control, 46(3), 76-81, 1999.

[20] Ali, A.H., El Sabagh, B. and Hassan, H.M. The role of waste products in increasing concrete strength and protecting against reinforcement corrosion. Corrosion prevention control, 45(6), 173-253, 1998.

[21] Al Sayed,, H.A., Ali, A.H., El Sababagh, B.A and Hasan, H.M. Role of an innovated waste products mix on environmental protection is a must, Alexandra, Egypt, 1998.

[22] Yang, C. Cao, G. Li, Y. Zhang, X, Ren, H. and Wang, X. A constructed alkaline consortium and its dynamics in treating alkaline blck liquor with every high pollution load. PLoS one, 3(11), Art No. e3777. 2008.

[23] Yang, C. Wang, Z., Li, Y., Niu, Y. Du, M. and He, X. Metabolic versatility of halotolerant and aalkaliphilic strains of Halomonas isolated from alkaline black liquor. Bioresource Technology, 101(17), 6778-6862.

[24] Yang, C. Niu, Y. Su, H, Wang, Z., Tao, F. and Wang, X. A novel microbial habitat of alkaline black liquor with very high pollution load: microbial diversity and the key members in application potentials. Bioresource Technology, 101(6), 1737-1781. 2010.

[25] Sclofani, D.A.S and Contrafatto, L. Experimental behavior of polyvinyl-alcohol modified concrete, Advanced Materials Research, 687, 155-160, 2013.

[26] Singh, N.K, Mishra, P.C, Singh, V.K. and Narang, K.K. Effect of HMPC on the properties of cement, Indian Journal of Chemical Technology, 9, 112, 2003.

[27] Otoko, G.R.and Ephraim, M.E. Concrete Admixture and set retardation potential of palm liquor, European International Journal of Science and Technology, 3(2), 2014.

[28] Ohama, Y., Recent progress in concrete-polymer composites. Journal of Advanced Cement Based Materials, 5(2), 31-40, 1997.
[29] Bright, R., Mraz, T. and Vassallo, J. The influence of various polymeric materials on the physical properties of a cementitious patching compound. ASTM Publication on Polymer-modified Hydraulic-cement mixtures, ed l.a. Kuhlman and D.G. Walters, 155-162, 1999.

[30] Shaker, F.A. El-Dieb, S.A, and Reda, M.M. Durability of styrenebutadiene latex modified concrete, Cement and Concrete Research, 27(5), 711-720, 1997.

[31] BS EN 197- Cement composition, Specifications and conformity criteria for cements, British Standards Institute, London, United Kingdom, 2011.

[32] BS 882- Specifications for aggregates from natural sources for concrete. British Standards Institute, London, United Kingdom, 1992

[33] BS 3148- Methods of test for water for making concrete. British Standards Institute, London, United Kingdom, 1980.

[34] BS 812-103.2. - Testing aggregates. Methods for determination of particle size distribution. Sedimentation Tests, British Standards Institute, London, United Kingdom, 1989.

[35] BS 12350-2 - Testing of concrete - Method for determination of slump, British Standards Institute, London, United Kingdom, 2009.

[36] BS EN 196-3 - Method of testing cement. Determination of setting time and soundness. British Standards Institute, London, United Kingdom, 1995.

[37] BS EN 12390-3- Testing of hardened concrete. Compressive Strength Test of Specimens. British Standards Institute, London, United Kingdom, 2009.

[38] BS EN 12390-5- Testing of Hardened Concrete. Flexural strength test of specimens. British Standards Institute, London, United Kingdom, 2000.

[39] BS EN 12390-6- Testing of hardened concrete. Tensile splitting strength Test of specimens. British Standards Institute, London, United Kingdom, 1983.

[40] BS 1881-122. Testing concrete. Method of determination of water absorption, British Standards Institute, London, United Kingdom, 2011.

[41] Naqash, J.A, Zahid, B.B, Mohammad, I.M., Subzar, A. and Dharvinder, K. Effect of accelerating admixture on properties of concrete, International Organisation of Scientific Research: Journal of Engineering, 4(3), 48-55, 2014.

[42] Yasuhiko, Y. Retarders for Concrete and their effects on setting time and shrinkage, 51, 1972.

[43] Medeiros, M. and Helen, P. Efficacy of surface hydrophobic agents in reducing water and chloride ion penetration in concrete., Materials and Structure, 41(9), 59-71, 2008.

[44] ASTM C140/C140M-17a Standard test methods for sampling and testing concrete masonry units and related units. 